\title{
The Aftermath of Hurricane Katrina
}

\section{Angela Khristin Brown}

\begin{abstract}
Hurricane Katrina was a natural disaster that had a negative response on the political, economic, sociological and environmental affects in America. In light of what happened, the levies should be rebuilt to become more secure, land sites should be cleaned up and small shops, restaurants and an historical museum should be made to preserve New Orleans culture. Many contributions should be made to recreate the atmosphere that was lost by Hurricane Katrina by many tourist who would visit this historic site to have a memorable experience of New Orleans culture.
\end{abstract}

Keywords: Hurricane Katrina; sociological constraints of Katrina; Aftermath of Katrina

\section{Council for Innovative Research}

Peer Review Research Publishing System

Journal: Journal of Advances in Linguistics

Vol 3, No. 1

editor@cirworld.com

www.cirworld.com, member.cirworld.com 


\section{Introduction}

Hurricane Katrina was the deadliest and most destructive Atlantic tropical cyclone of the 2005 Atlantic hurricane season. It was the costliest natural disaster, as well as one of the five deadliest hurricanes, in the history of the United States.

\section{Example:}

Early in the morning on August 29, 2005, Hurricane Katrina struck the Gulf Coast of the United States. When the storm made landfall, it had a Category 3 rating on the Saffir-Simpson Hurricane Scale-it brought sustained winds of 100-140 miles per hour-and stretched some 400 miles across. The storm itself did a great deal of damage, but its aftermath was catastrophic. Levee breaches led to massive flooding, and many people charged that the federal government was slow to meet the needs of the people affected by the storm. Hundreds of thousands of people in Louisiana, Mississippi and Alabama were displaced from their homes, and experts estimate that Katrina caused more than $\$ 100$ billion in damage.

\section{Main Results}

New Orleans is an historic land site. New Orleans, Louisiana is known for the madi-gras, jazz music, and sea food. It was known for as a vacation paradise to many. The location of New Orleans is an urban city off the Gulf port, on a peninsula, where there is a large body of water.

Hurricane Katrina was a natural disaster which had a negative outcome which affected the lives of all Americans. Being a natural disaster, the disaster could not be controlled because the effect was caused by nature. Measurements could have been determined to prepare for the disaster. If the news had informed its residence ahead of time, precautions could have been made to evacuate its residence on time. Environmental precautions could have also been made by changing the levy to prepare for the disaster.

The hurricane caused a sociological deprivation that resulted in economic devastation of the people who lived there. The people of New Orleans did not have the economic resources to rebuild. Most of the residents were poor people and did not have the funding to rebuild. There have been natural disasters where communities have come together to rebuild their community. The aftermath of poor health conditions would determine if there was a possibility to rebuild. There were a lot of hazards besides the water and wind after Katrina passed through. There were fires and explosions from exposed gas lines and electric wires were down too. A number of people were electrocuted days after the hurricane.

New Orleans did not have the funding or the support it needed to rebuild its community. The economy was negatively affected by the storm. There were many displaced workers and displaced families to find residence and work outside their communities. The damages to their homes could not be refurnished. Over 2,000 people were killed by Hurricane Katrina. It is impossible to quantify the damages of the storm.

The psychological impact of the storm of the residence in New Orleans will not be restored. There are communities of people have experienced a form of post-dramatic stress, facing the devastation of losing family, pets and friends to be relocated. For the people of New Orleans to experience the devastation of loss is a traumatic episode of disclosure that will remain in their lives forever. The memory of the storm is devastating in itself.

There was a statement to rebuild what was loss; but, no effort was made. The cost of rebuilding was too great. The people did not have the money to rebuild. The government could not afford to rebuild. The black community felt that the president did not care for poor black people who lived there. While efforts were made to rebuild in Tsunami or the effects of other national disasters were made, nothing could be done in America to rebuild a national historic site of New Orleans.

\section{Conclusions}

Hurricane Katrina was a natural disaster that had a negative response on the political, economic, sociological and environmental affects in America. In light of what happened, the levies should be rebuilt to become more secure, land sites should be cleaned up and small shops, restaurants and an historical museum should be made to preserve New Orleans culture. Many contributions should be made to recreate the atmosphere that was lost by Hurricane Katrina. Many tourist who would visit this historic site should have a memorable experience of New Orleans culture.

The people of New Orleans were deprived emotionally losing family, friends and their native communities. The people of New Orleans were deprived of the cultural environment that they were proud of in their communities. There was a rich heritage that was passed along generations and shared across cultures in their community which will never be obtained physically, and in its memory, its story must not be forgotten. 


\section{Works Cited}

[1] 11 Facts about Katrina. dosomething.org/actnow/tipsandtools/11-facts-about-hurricane-katrina. National Graphic. 2005

[2] Fast Facts Katrina. dosomething.org/.../11-facts-about-hurricane-katrina. Fox News. 2005

[3] Hurricane Katrina: Facts \& Summary/History. history.com/topics/hurricane-Katrina, A\&E Television Networks, LLC. 2014

[4] Hurricane Katrina: Facts, Damage \& Aftermath/Live Science. livescience.com/22522-hurricane-katrina-facts.html. Tech Media Network. 2014

[5] Hurricane Katrina. ncdc.noaa.gov/extreme events/special reports/Hurricane-Katrina. National Climatic Data Center. 2014

[6] Hurricane Katrina. en.wikipedia.org/wiki/Hurricane Katrina. Wikipedia. 2005 